\title{
Development of a Participatory Health Care Model for Farmers and Stakeholders Involved in Snakeskin Gourami Fish Farming in Bang Bo District, Samutprakarn Provinces, Thailand
}

\author{
Surawit NANTAPORN ${ }^{1, *}$, Ratchanee PIWPONG ${ }^{2}$, \\ Supaporn KONGPROM ${ }^{2}$, Thanyaporn CHATHOUAN ${ }^{1}$, \\ Sirinant CHANNAK ${ }^{4}$, Pavadee CHUAICHAROEN ${ }^{3}$, \\ Nopporn KURUSTIEN ${ }^{4}$, Kamontip KHUNGTUMNEAM ${ }^{2}$, \\ Chompunoot SINTHUPIBULYAKIT ${ }^{3}$, Kornwipa WIKAINAPAKUL ${ }^{3}$, \\ Sarawut SUTTIRAT ${ }^{3}$ and Vanida DURONGRITICHAI ${ }^{5}$
}

\author{
${ }^{1}$ Faculty of Public and Environmental Health, Huachiew Chalermprakiet University, \\ Samut Prakan 10540, Thailand \\ ${ }^{2}$ Faculty of Nursing, Huachiew Chalermprakiet University, Samut Prakan 10540, Thailand \\ ${ }^{3}$ Faculty of Medical Technology Huachiew Chalermprakiet University, Samut Prakan 10540, Thailand \\ ${ }^{4}$ Faculty of Physical Therapy, Huachiew Chalermprakiet University, Samut Prakan 10540, Thailand \\ ${ }^{5}$ Faculty of Nursing, Nakhon Pathom Rajabhat University, Nakhon Pathom 73000, Thailand
}

('Corresponding author's e-mail: surawitnanta@hotmail.com)

Received: 30 May 2019, Revised: 12 February 2020, Accepted: 28 March 2020

\begin{abstract}
The present study was based on a participatory action research (PAR) design with the objectives of developing a participatory health care model for farmers and stakeholders involved in snakeskin gourami fish farming in Bang Bo District. The study was conducted from May 1, 2017 - April 30, 2018. The sample was composed of 85 people who were fish farmers, fish pond owners, and fish farming laborers involved in the processing and distribution of snakeskin gourami, 35 VHVs (village health volunteers), 1 registered nurse, and 1 administrator of a Tambon Health Promoting Hospital (THPH) for a total of 122 subjects. The PAR process involved 3 stages: Stage 1- Situation Analysis, Stage 2 - Participatory Action Research Process, and Stage 3 - Outcome Evaluation.

The findings revealed 2 types of health problems: 1) work-related problems: incorrect work behaviors such as lifting heavy objects 1 - 5 times per day, repetitive work postures/positions causing aching bones and muscles and working fast to obtain large amounts and finish in time until work-related accidents occur such as knife cuts, pricked fingers from fish fins and slips/fallsand 2) Risks and illnesses caused by chronic disease. The synthesis of the participatory health care model disclosed that the health care activities covered 4 dimensions, encompassing health promotion, disease prevention, treatment, and recovery. The sample had a high level of satisfaction in the organization of the project at a mean of 4.40 of 5 points.
\end{abstract}

Keywords: Bang Bo snakeskin gourami, Farmers and stakeholders involved in snakeskin gourami fish farming, Health problems, Participatory health care model, Participatory action research (PAR) 
http://wjst.wu.ac.th

\section{Introduction}

Due to the national policy for local economic development to promote the creation of occupations in communities based on the sufficiency economy concept, not a few people have made upgrades or changes in previous livelihoods handed down from generation to generation in the form of cottage industries and turned to commercial production. Snakeskin gourami fish farming is a type of local wisdom or intellect in terms of occupations in which valuable experience is handed down from generation to generation. Fragrant snakeskin gourami fish is considered an important product of local wisdom that generates income, builds a good reputation, and is a matter of pride for people in many areas [1]. Khlong Dan, Bang Bo, Samutprakarn, is an area where snakeskin gourami fish farming has been done continually. The snakeskin gourami fish from this area can be sold fresh and has been processed for a long time for its delicious, unique flavor. The agencies involved have exerted efforts toward promoting snakeskin gourami fish farming in Bang Bo in terms of production and processing by supporting production to meet OTOP standards. Besides, the $12^{\text {th }}$ National Economic and Social Development Plan $(2017-2021)$ contains specific key strategies and development guidelines such as the development of a strong and sustainable agricultural sector, building and transferring academic, scientific, technological, and innovative knowledge and local wisdom on participatory agriculture [2]. In promoting effective farming and processing while achieving the goal of inheriting the identity of local wisdom on snakeskin gourami fish farming, people working in occupations involving snakeskin gourami fish farming and processing are important because these people are the main factor driving the system and production mechanisms from the beginning of farming until snakeskin gourami fish become products for consumers. The main steps are pond preparation, feeding, water quality care, disease prevention, and adding value by processing snakeskin gourami fish into fragrant snakeskin gourami fish before distribution in a full cycle [3].

Farmers and stakeholders involved in snakeskin gourami fish farming are considered informal labor, or people who work without protection and social security, which makes them different from work by formal labor under the Labour Protection Act with no measures controlling correct practice based on work principles and no tangible systems for managing occupational health, safety and environment [4]. According to the literature review, a large amount of academic evidence confirmed occupational health and safety problems due to informal labor. Work-related diseases and injuries can occur from workers, work characteristics, and health threats due to work environment hazards [5]. According to a study of problems in work environments most frequently encountered by informal workers such as work habits, odors, insufficient lighting, toxic chemicals, and dangerous machinery [6]. In addition to work-related health problems, farmers and stakeholders are also at-risk for health problems from behaviors in daily life, particularly chronic non-communicable diseases (NCDs) such as hypertension and diabetes mellitus. The incidence rates of the aforementioned diseases are well-known to be escalating and creating the greatest burdens from annual health losses, thereby causing an impact on national development in terms of burdens from nursing expenses and lost productivity. According to data from the Ministry of Public Health in 2015, Thailand spent 198,152 million baht in medical costs and other expenses incurred by illness per year, or 2.2 percent of the country's income [7].

Therefore, the research team prepared the research project on participatory health care development model of Bang Bo district farmers and stakeholders involved in snakeskin gourami fish farming to develop and prepare healthcare plans/projects for snakeskin gourami fish farmers and stakeholders from participation by stakeholders in every sector, including health agencies, local agencies and education institutes to help farmers and stakeholders involved in snakeskin gourami fish farming have good health, which is a basic factor supporting quality production, long-term income generation, and sustainable occupations. 


\section{Materials and methods}

The present study was participatory action research (PAR) in which the research methodology was divided into 3 stages:

Stage 1 - The situation of health problems was analyzed by surveying the health conditions and searching for health-related problems and needs in addition to determining the factors influencing the health conditions of snakeskin gourami fish farmers and stakeholders and organizing health services and in-depth discussions with snakeskin gourami fish farmers and stakeholders, district MoPH THPH staff, Klong Dan TAO staff, and district farmers to compile and analyze data on health problems.

Stage 2 - The participatory health care model was developed in 5 steps: Step 1 - Good rapport was built by chatting or holding group discussions at the meetings of the organizations or agencies involved in health care; Step 2 - Public forums were organized to reflect on the data concerning the situation of the health problems identified in Phase 1 among snakeskin gourami fish farmers and stakeholders in order to acknowledge and raise awareness about the problems in proceeding with the development and revisions of the model, including the drafting of the participatory health care model for snakeskin gourami fish farmers and stakeholders as follows: proposing the model and methods for carrying out health promotion and health care in the aspects of health promotion, occupational safety, ergonomics and psychosocial factors; Step 3 - Organizing health promotion and health care projects based on the health development plans; Step 4 - Evaluating the results of the projects/activities performed and making revisions in the health development plans then synthesizing the health care model; Step 5 - Public consideration of the project's health development plans/activities and health care model.

Stage 3 - Outcome Evaluation: health care model and synthesis of the participatory health care model for Bang Bo snakeskin gourami fish farmers and stakeholders. There is a process to find a target group for providing care and classifying the target group so that care can be provided following the problems and needs. The synthesis of health care activities coverage of the following 4 dimensions: health promotion, disease prevention, treatment, and recovery $[8,9]$.

The sample of fish farmers, fish pond owners, and fish farming laborers, processors and distributors was selected by using the method of accidental sampling. The sample size was calculated by using a computer program, setting error at $\alpha=0.05$ and power of test at power $(1-\beta=0.80)$. A sample size of 85 subjects was obtained.

The instruments used in the researcher included 3 types of questionnaires: 1) A record for the factors influencing the health conditions based on risk factors composed of 4 main parts: 1.1) demographic data; 1.2) types of work performed; 1.3) data on health condition based on individual risk factors, namely, work-related, daily lifestyle, ergonomic and psychosocial factors and 1.4) healthpromoting factors; 2) record for data collection and line of questioning for in-depth discussions with snakeskin gourami fish farmers and stakeholders, THPH, district MoPH staff, Khlong Dan TAO staff. The line of questioning was composed of questions on health problems, health care service system, need for the organization of health services, and 3) record for collecting data on laboratory blood test results on glycemic levels, blood cholesterol levels (cholesterol, triglyceride, HDL-C, LDL-C, and uric acid levels.

The validity was tested for the structure and content of the questions by 3 experts in nursing, physical therapy, and occupational health and safety. Then, the reliability of the questionnaires was tried in a sample of 30 subjects possessing the same characteristics of the sample for the present study and a Chronbach's alpha coefficient value of over 0.80 was obtained.

The present study was certified by the Institutional Review Board on Ethics in Research Involving Human Subjects of Huachiew Chalermprakiet University between May 23, 2017 - May 22, 2019 and consent was obtained from the sample for data collection. All of the participants in the study signed informed consent forms for participation before the data collection began.

The statistics used in data analysis were number, percentage, mean and standard deviation. For the quantitative data analysis, the researcher used descriptive statistics composed of percentage, mean, and standard deviation. For the qualitative data analysis, the researcher used the method of transcribing the content of the in-depth discussions for use in interpreting the data obtained and accurately identifying the 
http://wjst.wu.ac.th

main themes reliably. The researchers, then, analyzed the qualitative data by using content analysis together with thematic analysis and data triangulation.

\section{Results and discussion}

The outcome of the process for developing a participatory health care model for farmers and stakeholders involved in snakeskin gourami fish farming in Bang Bo District was carried out in 3 phases:

Stage - 1: The situation of health problems was analyzed based on the data collected from the group of snakeskin gourami fish farmers and stakeholders ( 85 people). According to the findings on personal characteristics most of the sample was female, aged between 41 - 50 years, married status, primary education levels, and Monthly income/person less than or equal to 10,000 baht (Table 1).

Table 1 Demographic characteristics of farmers and stakeholders involved in snakeskin gourami fish farming in Bang Bo District $(n=85)$.

\begin{tabular}{|c|c|c|c|c|c|}
\hline Characteristic & $n$ & $\%$ & Characteristic & $n$ & $\%$ \\
\hline Gender & & & \multicolumn{3}{|l|}{ Education } \\
\hline Male & 20 & 23.53 & Before Primary School & 9 & 10.59 \\
\hline Female & 65 & 76.47 & Primary School & 53 & 62.35 \\
\hline Age (Years) & & & Junior High School & 10 & 11.76 \\
\hline$\leq 30$ & 13 & 15.29 & Senior High School & 8 & 9.41 \\
\hline $31-40$ & 10 & 11.76 & High Vocational Certificate & 4 & 4.71 \\
\hline $41-50$ & 28 & 32.94 & Bachelor Degrees & 1 & 1.18 \\
\hline $51-60$ & 24 & 28.24 & Monthly Income /Person (Bath) & & \\
\hline$\geq 61$ & 10 & 11.76 & $\leq 10,000$ & 49 & 57.60 \\
\hline Mean $=46.66 \mathrm{SD}=12.44$ & $\operatorname{Max}=70$ & $\operatorname{Min}=17$ & $10,001-20,000$ & 26 & 30.60 \\
\hline Marital Status & & & $20,001-30,000$ & 6 & 7.10 \\
\hline Single & 11 & 12.94 & $\geq 30,001$ & 4 & 4.70 \\
\hline Married & 68 & 80.00 & Mean $=12,703.53 \quad \mathrm{SD}=8,670.12$ & $\operatorname{Max}=$ & 000 \\
\hline $\begin{array}{l}\text { Widowed/ } \\
\text { Divorcee/Separated }\end{array}$ & 6 & 7.06 & $\operatorname{Min}=3,000$ & & \\
\hline
\end{tabular}

Based on the data collected from both the questionnaire on health condition and the factors influencing the health conditions of the 85 farmers and stakeholders involved in Bang Bo snakeskin gourami fish farming and interviews with the 35 VHVs in the area, the registered nurse at the Tambon Health Promoting Hospital (THPH) and the results from the physical examinations and blood test results in 47 people discovered health problems divided into 2 types of issues, namely, work-related health problems and problems related to risks and illnesses caused by chronic disease as follows:

Work-Related Health Problems - Incorrect work behavior in which the characteristics of the work mostly involved putting fish out to dry/selling-scaling fish/cutting fish heads and lifting fish crates. The laborers work every day for $6-10 \mathrm{~h}$ per day. The most frequently used work postures were sitting and regularly lifting objects with weights of 1 - 10 kilograms $1-5$ times per day. The most frequently encountered unusual symptoms were backaches, knee aching, and general achiness throughout the body. Most of the work-related accidents currently encountered occur as a result of negligence. Symptoms of sore bones and muscles were managed by purchasing oral or topical medications. The injuries associated with the processes of raising snakeskin gourami fish were found to have occurred over the 3 months preceding the data collection. The types of injuries most frequently encountered were sprains, stiffness, 
http://wjst.wu.ac.th

bruising, cuts, and eye irritations. Furthermore, almost half of the sample was found poor to moderate levels of knowledge and engagement in work-related risk prevention. For the most part, the scores for psychological conditions ranged from poor to moderate level.

The sample was found to have the following problems of risks and injury/illness due to chronic disease: body mass index (BMI) at the obese level $\left(>25 \mathrm{~kg} / \mathrm{m}^{2}\right)$; abnormal blood cholesterol for HDL-C, LDL-C, and cholesterol; smoking and alcohol consumption. The sample also had the following chronic diseases: high blood cholesterol; hypertension and diabetes mellitus with family history of chronic disease (Table 2).

Table 2 Blood test report of farmers and stakeholders involved in snakeskin gourami fish farming in Bang Bo District $(n=47)$.

\begin{tabular}{|c|c|c|c|c|c|c|c|c|c|}
\hline \multirow{3}{*}{$\begin{array}{c}\text { Health } \\
\text { Examination List }\end{array}$} & \multicolumn{4}{|c|}{ Blood Test report } & \multirow{3}{*}{$\begin{array}{c}\text { Health } \\
\text { Examination List }\end{array}$} & \multicolumn{4}{|c|}{ Blood Test report } \\
\hline & \multicolumn{2}{|c|}{ Abnormal } & \multicolumn{2}{|c|}{ Normal } & & \multicolumn{2}{|c|}{ Abnormal } & \multicolumn{2}{|c|}{ Normal } \\
\hline & $n$ & $\%$ & $\mathrm{n}$ & $\%$ & & $n$ & $\%$ & $\mathrm{n}$ & $\%$ \\
\hline 1. Glucose & 10 & 21.28 & 37 & 78.72 & 4. HDL-C & 36 & 76.60 & 11 & 23.40 \\
\hline 2. Cholesterol & 29 & 61.70 & 18 & 38.30 & 5. LDL-C & 35 & 74.47 & 12 & 25.53 \\
\hline 3. Triglyceride & 14 & 29.79 & 33 & 70.21 & 6. Uric acid & 12 & 25.53 & 35 & 74.47 \\
\hline
\end{tabular}

Furthermore, health literacy was insufficient in terms of general health knowledge about selfpractice, access to information and health services, skills for accessing information and health services, communication skills, management skills, and self-care behavior. Health care needs were free health examination services, community health examinations at least once per month, and screening for patients with hypertension, diabetes mellitus, and cervical cancer in addition to the need for projects promoting the prevention of NCDs with instruction, advice and consultation about work-related injuries and illnesses, training about massage methods, lessons about exercises aimed at relaxation from sitting in the same position at work for long periods and campaigns against littering in canals to prevent wastewater in canals, etc.

Stage - 2: Results from the Development of the Participatory Health Care Model

Step 1 - Chatting together or holding larger group discussions at meetings of the organizations or agencies involved with health care attended by the chief officer of the Khlong Dan TAO, chief of the Khlong Dan TAO Public Health Department, administrators from the TAO health-promoting hospital and staff nurses from the TAO health promoting hospital.

Step 2 - Organization of a public forum for reflecting on the health information. The forum was attended by Khlong Dan TAO staff, administrators, and registered nurses from the TAO health promoting hospital, VHVs, snakeskin gourami fish farmers, and processors. The forum resulted in plans for developing the health of snakeskin gourami fish farmers and stakeholders. The discussion and presentation of concepts included the type and method for executing the health promotion and health care project covering all 4 dimensions, namely, health promotion, occupational safety, ergonomics, and psychosocial aspects. The draft of the plans for health development was composed of 4 projects/activities, 9 sub-activities in the form of proactive and defensive projects in local areas. The types of activities included promotion, prevention, treatment, and recovery of health in the occurrence of chronic diseases and work-related diseases or injuries. The target groups for the development were health care leaders (VHVs) in addition to farmers and stakeholders involved in snakeskin gourami fish farming. Furthermore, each project was integrated with the curriculum for instruction in the Huachiew 
http://wjst.wu.ac.th

Chalermprakiet University health science group to ensure that students and communities learn about the projects. plans.

Step 3 - Organization of health-promoting and health care projects based on health development

Step 4 - Evaluation of the results yielded by completed projects/activities and revisions in health development plans with the synthesis of health care models, the results yielded by the organization of training to provide knowledge for developing the competency of leaders in health promotion and training to increase knowledge and raise awareness among snakeskin gourami fish farmers and stakeholders. The training was organized in the form of lectures and demonstrations with hands-on practice with teaching aids to accompany the training such as posters, flipcharts, and brochures, etc. in addition to exchanges of lessons learned and the experience of the participants in the training. The topics covered by the training included 3 Or. 2 Sor. knowledge and behavior, selection of teaching aids, and dissemination of information about health care to other people, including the health risk prevention in both daily life and working, making adjustments in postures and exercise methods for relief or prevention of soreness/aching. The activities organized were integrated with lessons composed of nursing subjects, medical techniques, physical therapy, and basic occupational health and safety. As a result, the students in the organization were able to apply the lessons learned to use and practice with real experience in working together with people in the community and building a good rapport with students on multidisciplinary teams. The results of the project evaluation were as follows:

For the VHVs, the project provided knowledge and training about the 3 Or. 2 Sor. Principles, occupational safety, ergonomics, and psychosocial aspects. All 35 VHVs participated in the project. After participating in the project, all VHVs can self-assess physical and mental health problems. For the most part, had increased knowledge of basic in occupational health and safety $(62.20 \%)$ and knowledge of ergonomics principle $(91.40 \%)$. For satisfaction after participation in the project was at the highest level with a score of 4.56 points from a total of 5 points and 3 of the VHVs were outstanding models of health care.

The project provided instruction about general knowledge concerning health promotion based on the 3 Or. 2 Sor. Basic of occupational Health and safety in terms of ergonomics and psychosocial aspects. There were 50 participants in the project composed of people involved in health care (12\%) and other people such as vendors, police, housewives, shrimp farmers and those who did not reply, etc. (52\%) and stakeholders involved in snakeskin gourami fish farming (36 \%) such as snakeskin gourami fish farmers snakeskin gourami processors and snakeskin gourami vendors. The level of satisfaction about the organization of the project was high at a mean of 4.40 points from a total of 5 points. Two of the farmers and stakeholders involved in Bang Bo snakeskin gourami fish farming made adjustments in their workplaces based on the ergonomic principles for the laborers of snakeskin gourami fish processors by adding seats and raising the heights of cutting boards then comparing the level of risk before and after making the adjustments in the workplace (Figure 1). According to the findings after making the aforementioned adjustments in the workplace based on LUBA assessment scores (An assessment technique for postural loading on the upper body) [10], Research Participant 1 was able to lower the score to 27 points and the score on the assessment of risk factors based on the ART tool (tool for assessment of repeated tasks) [11] was reduced to 29 points. Nevertheless, based on both assessment forms, the findings continued to show that Research Participant 1 remained within the criteria for high risk, while the LUBA score for Research Participant showed a greater reduction than Research Participant 1 at 22 points and the score for the ART tool was 32 points. Research Participant 2 continued to fall within the criteria for high risk and also needed to make adjustments in work postures/positions. Overall, mean satisfaction after making adjustments in the work was at a good level (4.50 points) (Tables 3 - 4). 
http://wjst.wu.ac.th
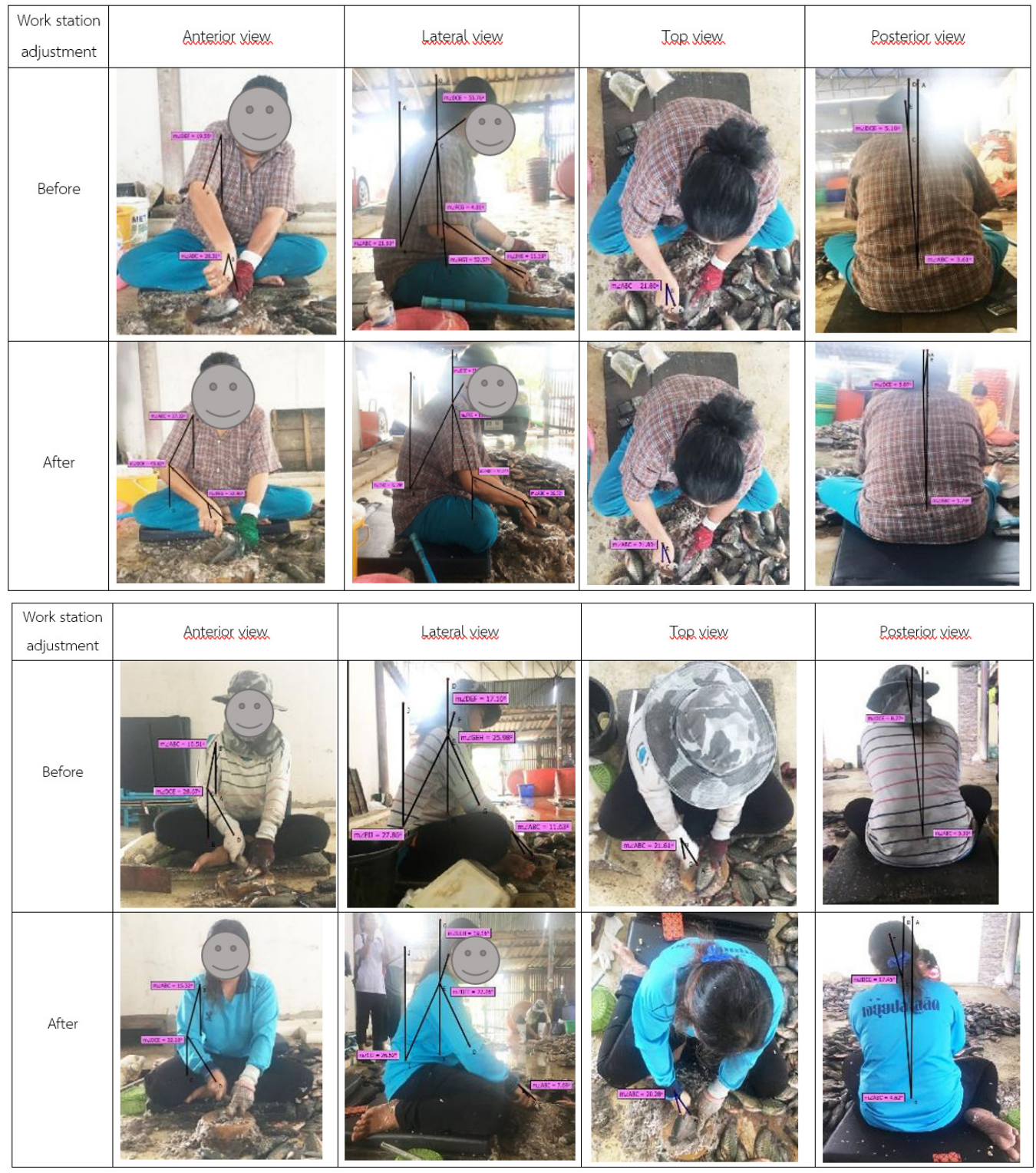

Figure 1 Illustrates the assessment of work postures of research participants before and after adjustments had been made in the workplace.

Table 3 Comparison risk level of working posture between before and after making adjustments in work station of snakeskin gourami fish processors based on LUBA assessment.

\begin{tabular}{|c|c|c|c|c|c|}
\hline $\begin{array}{c}\text { Participant } \\
\text { No. }\end{array}$ & $\begin{array}{l}\text { Before } \\
\text { (Point) }\end{array}$ & Interpreted & $\begin{array}{c}\text { After } \\
\text { (Point) }\end{array}$ & Interpreted & $\begin{array}{l}\text { Difference } \\
\text { Point }\end{array}$ \\
\hline 1 & 28 & $\begin{array}{l}\text { Must be adjust working } \\
\text { posture immediately }\end{array}$ & 27 & $\begin{array}{l}\text { Must be adjust working } \\
\text { posture immediately }\end{array}$ & 1 \\
\hline 2 & 22 & $\begin{array}{l}\text { Must be adjust working } \\
\text { posture immediately }\end{array}$ & 22 & $\begin{array}{l}\text { Must be adjust working } \\
\text { posture immediately }\end{array}$ & 0 \\
\hline
\end{tabular}


http://wjst.wu.ac.th

Table 4 Comparison risk level of upper limb on repeated tasks between before and after making adjustments in the work station of snakeskin gourami fish processors based on ART Tool.

\begin{tabular}{cccccc}
\hline $\begin{array}{c}\text { Participant } \\
\text { No. }\end{array}$ & $\begin{array}{c}\text { Before } \\
\text { (Point) }\end{array}$ & Interpreted & $\begin{array}{c}\text { After } \\
\text { (Point) }\end{array}$ & Interpreted & $\begin{array}{c}\text { Difference } \\
\text { Point }\end{array}$ \\
\hline 1 & 33 & High risk level & 29 & High risk level & 4 \\
2 & 40 & High risk level & 32 & High risk level & 8 \\
\hline
\end{tabular}

Step 5 - Public consideration of the health development project plans/activities and the health care model: the drafting of the participatory health care model for Bang Bo snakeskin gourami fish farmers and stakeholders was the result of participation and exchanges of opinions in the participant network and Bang Bo snakeskin gourami fish farmers and stakeholders. Furthermore, results of the evaluation of Steps 1-3 were considered in combination with the synthesis of the participatory health care model for Bang Bo snakeskin gourami fish farmers and stakeholders as suitable for the working conditions and problems occurring in the future.

Stage 3 - Outcome Evaluation: Participatory health care model and synthesis of healthcare models for snakeskin gourami fish farmers and stakeholders. The researcher synthesized the participatory health care model for farmers and stakeholders involved in Bang Bo snakeskin gourami fish farming with the following processes:

1) The target population for providing care was divided into 3 levels. At the personal level, the target population was divided into 3 groups. Each Bang Bo snakeskin gourami fish farmer had different health problems and different care needs. Snakeskin gourami fish farmers were divided into the following 3 groups: 1) healthy fish farmers with no chronic diseases; 2) at-risk fish farmers with work-related chronic diseases and illnesses; and 3) sick fish farmers with chronic diseases such as hyperlipidemia, hypertension, and diabetes. The target population at the family level was family members with a history of chronic diseases and the target population at the community level was wastewater created in the processing of snakeskin gourami fish or waste disposal in canals.

2) 4-Dimensional Family Health Care Activity - Health promotion, disease prevention, treatment, and recovery, all of which were organized. The health care activities had to be consistent with each target group. The target population was divided into the following 3 groups: 1) In the healthy group, the focus was placed on health promotion. Care activities consisted of annual health checkups, education, recommendations, and consultation on prevention of work-related diseases, work safety, a social mind, and provide 3 Or. and 2 Sor. knowledge.

3) In the at-risk group, the focus was placed on prevention of illness with care activities such as health screening, campaigning against eating rich or spicy foods, prevention of hypertension and diabetes mellitus, shop inspections/snakeskin gourami fish processing inspections with care for consumer health, education, recommendations and consultation on work-related illness prevention, work safety, a social mind, instruction on wound dressing/first aid when injuries occur and 3) In the sick group, the focus was placed on treatment and rehabilitation to prevent complications from the disease with care activities such as coming to be examined at appointments, medication adherence under doctor's orders, providing selfcare recommendations for during a chronic illness and follow-up home visits.

4) Success in community healthcare is not usually caused by the work of any single person but through cooperation from many sectors on the issue of community health. Community healthcare should use participant networks to care for community health because each organization has different experiences and healthcare roles and duties. Using the capabilities of each organization will enable healthcare for community members with coverage. Each organization had healthcare roles (Table 5). 
http://wjst.wu.ac.th

Table 5 Shareholders/participant networks and roles in health care for farmers.

\begin{tabular}{|c|c|}
\hline $\begin{array}{l}\text { Shareholders/Partici } \\
\text { pant Network }\end{array}$ & Roles in Health Care for Farmers \\
\hline 1. Employers & $\begin{array}{l}\text { - Expenses for injuries occurring in the work of raising and processing snakeskin } \\
\text { gourami fish with sanitary procedures. } \\
\text { - Prevention of accidents or risks in raising and processing snakeskin gourami } \\
\text { fish. }\end{array}$ \\
\hline 2. TAOs & $\begin{array}{l}\text { - Campaigns for preventing wastewater occurring from snakeskin gourami fish } \\
\text { processing; campaigns against littering canals and inspecting shops where } \\
\text { snakeskin gourami fish are processed. }\end{array}$ \\
\hline $\begin{array}{l}\text { 3. THPHs } \\
\text { 3.1) Promotion \& }\end{array}$ & $\begin{array}{l}\text { - Projects for the care, prevention, and basic treatment of aching muscles. } \\
-3 \text { Or. } 2 \text { Sor. Instruction. }\end{array}$ \\
\hline Prevention & $\begin{array}{l}\text { - Campaigns about eating rich, strongly flavored foods, prevention of } \\
\text { hypertension and diabetes mellitus. } \\
\text { - Services for health examinations/screening for cervical cancer, hypertension } \\
\text { and diabetes mellitus in communities and among people with difficulty } \\
\text { accessing the health service system such as elderly people, bedridden } \\
\text { patients and people living far from hospitals. } \\
\text { - Provision of instruction, advice and consultation about the prevention of } \\
\text { work-related diseases, occupational safety and psychosocial aspects. }\end{array}$ \\
\hline 3.2) Treatment & - Lessons on dressing wounds/first aid when injuries occur. \\
\hline 3.3) Recovery & - Self-care for illnesses related to chronic disease. \\
\hline 4. VHVs & $\begin{array}{l}\text { - Testing of glycemic levels, blood pressure monitoring, serving as models of } \\
\text { proper health care and health literacy. }\end{array}$ \\
\hline $\begin{array}{l}\text { 5. Educational } \\
\text { Institutions }\end{array}$ & $\begin{array}{l}\text { - Organization of projects for integrating academic services and instruction by } \\
\text { working together with multidisciplinary teams. }\end{array}$ \\
\hline
\end{tabular}

The synthesis of the participatory health care model for farmers and stakeholders involved in Bang Bo snakeskin gourami fish farming can be summarized as shown in Figure 2 below.

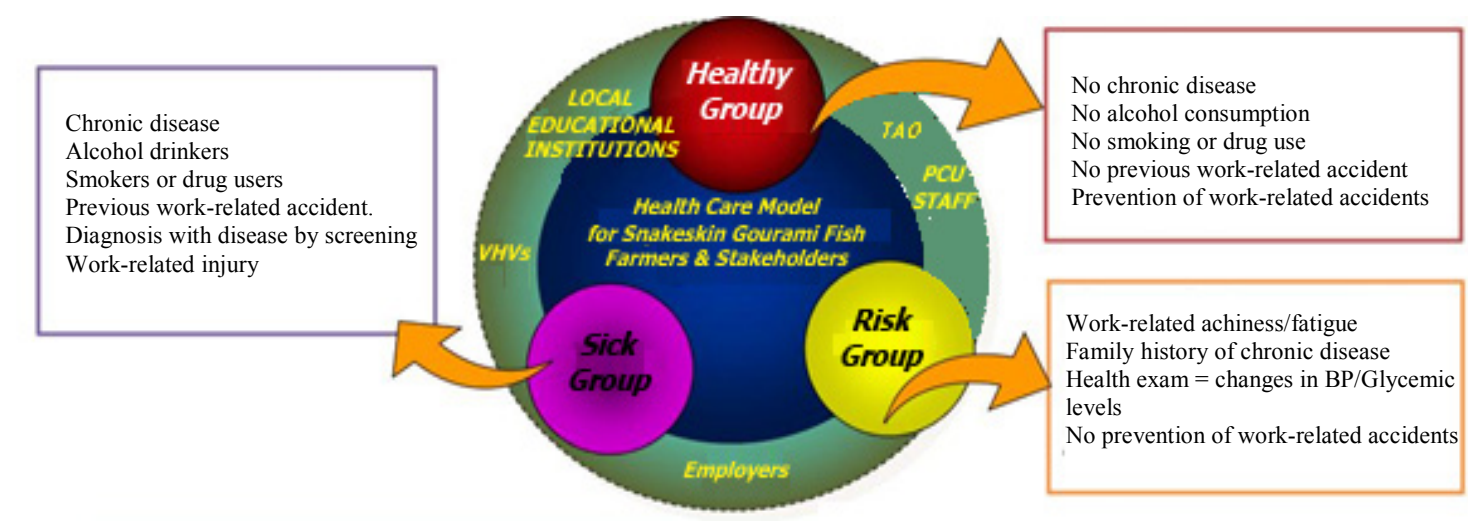




\begin{tabular}{|c|c|c|c|c|c|c|c|}
\hline \multicolumn{2}{|c|}{$\begin{array}{c}\text { Tambon Health } \\
\text { Plan }\end{array}$} & $\begin{array}{c}\text { Farmers \& } \\
\text { Families }\end{array}$ & TAO & ТНРН & VHV & Employers & $\begin{array}{l}\text { Educational } \\
\text { Institutions }\end{array}$ \\
\hline Healthy & $\begin{array}{l}\text { Focus: } \\
\text { Health } \\
\text { Promotion }\end{array}$ & $\begin{array}{l}\text { Self-care by } \\
3 \text { Or. } 2 \text { Sor. }\end{array}$ & $\begin{array}{l}\text { Supports health- } \\
\text { related projects }\end{array}$ & $\begin{array}{l}\text { Annual } \\
\text { health } \\
\text { check-ups }\end{array}$ & $\begin{array}{l}\text { Campaigns } \\
\text { for } \\
\text { offering } \\
\text { advice }\end{array}$ & $\begin{array}{l}\text { Opportunities for } \\
\text { annual health check- } \\
\text { ups } \\
\text { Establish committee } \\
\text { to reduce work- } \\
\text { related accidents }\end{array}$ & $\begin{array}{l}\text { Hold } \\
\text { educational } \\
\text { projects by } \\
\text { multidisciplinary } \\
\text { teams }\end{array}$ \\
\hline At Risk & $\begin{array}{l}\text { Focus: } \\
\text { Prevention }\end{array}$ & $\begin{array}{l}\text { Reduce risks } \\
\text { factors; } \\
\text { annual health } \\
\text { check-ups }\end{array}$ & $\begin{array}{l}\text { Campaigns for } \\
\text { preventing } \\
\text { work-related } \\
\text { disease/accidents }\end{array}$ & $\begin{array}{l}\text { Home } \\
\text { visits } \\
\text { Self-care } \\
\text { promoting } \\
\text { activities }\end{array}$ & $\begin{array}{l}\text { Home } \\
\text { visits; } \\
\text { collection } \\
\text { of health } \\
\text { data }\end{array}$ & $\begin{array}{l}\text { Initiate health check- } \\
\text { ups/screening } \\
\text { Arrange } \\
\text { environmental } \\
\text { equipment conducive } \\
\text { to work }\end{array}$ & $\begin{array}{l}\text { Hold } \\
\text { educational } \\
\text { projects on } \\
\text { reducing risks } \\
\text { by } \\
\text { multidisciplinary } \\
\text { teams }\end{array}$ \\
\hline Sick & $\begin{array}{l}\text { Focus: } \\
\text { Treatment }\end{array}$ & $\begin{array}{l}\text { Take } \\
\text { medication; } \\
\text { continual } \\
\text { check-ups }\end{array}$ & $\begin{array}{l}\text { Supports } \\
\text { ambulances to } \\
\text { and from } \\
\text { hospital }\end{array}$ & $\begin{array}{l}\text { Home } \\
\text { visits for } \\
\text { basic } \\
\text { treatment }\end{array}$ & $\begin{array}{l}\text { Home } \\
\text { visits; } \\
\text { transfer of } \\
\text { data to } \\
\text { THPH }\end{array}$ & $\begin{array}{l}\text { Allow time for } \\
\text { treatment }\end{array}$ & $\begin{array}{l}\text { Home visits } \\
\text { with THPH and } \\
\text { multidisciplinary } \\
\text { teams }\end{array}$ \\
\hline
\end{tabular}

Figure 2 shows the participatory health care model for farmers and stakeholders involved in Bang Bo snakeskin gourami fish farming.

\section{Discussion}

The development of the participatory health care model for farmers and stakeholders involved in Bang Bo snakeskin gourami fish farming began during the early phase by conducting a survey of health conditions and a search for the health-related factors, problems, and needs influencing the health conditions of snakeskin gourami fish farmers and stakeholders. The aforementioned activities involved collecting data from farmers, employers, VHVs, and Tambon Health Promoting Hospital (THPH) staff on the health problems occurring. In searching for the problems, all sectors involved in community health care owned the issue of community health-related to the development of good health among community members in line with the study conducted by Phalasuek et al. [12]. In analyzing problems and situations in communities, stakeholders were allowed to present and exchange opinions and problem-solving needs to help every person perceive the current problem situation, thereby leading to appropriate solution designs as suitable for the problem. The process of developing a participatory health care model began with building participation, good rapport, meeting with snakeskin gourami fish farmers and stakeholders from influential community members. This was consistent with Kokpol [13] who stated that meetings and discussions were a technique for building public participation, trust, and good rapport because informal meetings and discussions help to create relaxation and more convenient communication. Good participation needs to come from the willingness and intention to participate because the aforementioned factors will create feelings of being part of the community in solving that problem.

The preparation of the draft of the participatory health development plan for snakeskin gourami fish farmers and stakeholders and public hearings to reflect on the data in the first stage was aimed at exchanging opinions on seeking solutions by using the strong points of all related parties and using the opinions of all stakeholders to prepare the health development plan. This was consistent with Phalasuek et al. [12] who conducted a study on community participatory processes for solving the problem of adolescent pregnancy by drawing upon community power from participation by community leaders in seeking solutions for problems from community costs and resources while building community strength. Participation in activities, sufficient news, information exchanges, participation in expressing opinions and effects from participation by stakeholders in the community enabled the planning to solve health problems, thereby leading to a gathering of health networks and partners. In addition to transferring 
http://wjst.wu.ac.th

knowledge to people, behaviors need to be adjusted in order to enable nurses to become health leaders who will adjust the behaviors of farmers and stakeholders involved in snakeskin gourami fish farming. In this study, the researcher organized activities for VHVs to analyze VHVs' health to build perception of personal risk factors for the incidence of disease. This was consistent with a study conducted by Wichianprapha, Homsin and Srisuriyawet [14] who stated that the development of village health volunteers to engage in proper health behaviors requires an emphasis on the promotion of perceived selfefficacy and perceived health risks, including training to continually increase knowledge and skills for village health volunteers.

The work plans had indicators of success from the VHVs, who were satisfied with their participation in the project at the highest level and gained additional knowledge about occupational safety. However, some of the VHVs were found to have health conditions putting them at risk for chronic diseases such as obesity and health problems related to chronic diseases. In the present study, short-term outcomes were evaluated. In other words, the VHVs perceived the factors putting them at risk for physical and psychological maladies. Furthermore, knowledge was evaluated after participation in the project concerning occupational safety with further evaluation of satisfaction. According to the findings, the VHVs had increased knowledge after participating in the project in addition to the highest level of satisfaction, while the farmers and stakeholders involved in snakeskin gourami fish farming only had evaluations of satisfaction, which was also at the highest level. The above findings are congruent with the findings of a study by Sukmark, Promsiripaiboon, and Pechmanee [15], who studied the effects of a program for developing leadership competency among village health volunteers in the area of consumer protection by evaluating the outcomes after completion of the program. According to the findings, the VHVs were found to have increased competency with a high level of satisfaction. Thepphukhieo and Daenseekaew [16], who explored community participation in protection against the use of pesticides in ornamental flower cultivation for flowers used to make wreaths of flowers, chemical usage behavior was measured at 3 months after the project had ended. The findings also revealed that flower farmers had increased safe chemical use and reduced the amount of chemical accumulations in the body.

The synthesis of the participatory health care model for farmers and stakeholders involved in snakeskin gourami fish farming in Bang Bo required finding a target group for providing care. The main target group can be divided into 3 groups of snakeskin gourami fish farmers as follows: 1) The group in good health, namely, the group with no chronic diseases; 2) The risk group, namely, the group with chronic diseases and work-related illnesses and 3) The sick group, namely, the group with chronic illnesses due to chronic disease. The target groups were categorized to achieve care suitable for solving the health care problems and needs identified based on the perspectives and beliefs of each person [8]. The health care activities should provide coverage of the following 4 dimensions: health promotion, disease prevention, treatment, and recovery because each target group required different types of health care. The target population groups were arranged based on age, health, and health problems as follows: the group in good health, the group with illness. The groups were also categorized based on specific needs with greater emphasis on proactive health care contexts than defensive and focus on service provision concerning disease prevention and health promotion, offering assistance to patients, families, and communities with tangible solutions for health problems [9].

\section{Conclusions}

The development of the participatory health care model for farmers and stakeholders involved in Bang Bo snakeskin gourami fish farming began by surveying health conditions and health-related risk factors for collected data to prepare a draft of the participatory health development plan and reflect on the data was aimed at exchanging opinions on seeking solutions by using the strong points of all related parties and stakeholders to prepare the health development plan. The work plans had indicators of success from the VHVs, who had increase knowledge about health risk prevention from training in the health care project provided instruction about general knowledge concerning health promotion based on the 3 Or. 2 Sor. basic of occupational health and safety in terms of ergonomics and psychosocial aspects for 
http://wjst.wu.ac.th

communication to farmers and stakeholders involved in snakeskin gourami fish farming. The synthesis of the participatory health care model for farmers and stakeholders involved in snakeskin gourami fish farming in Bang Bo required finding a target group as follows: 1) The group in good health, namely, the group with no chronic diseases; 2) The risk group, namely, the group with chronic diseases and workrelated illnesses and 3) The sick group, namely, the group with chronic illnesses due to chronic disease. The target groups were categorized to achieve care suitable for solving the health care problems found that the health care activities covered the following 4 dimensions: health promotion; disease prevention; treatment and recovery. As well, all activities in the health care model were successful need to participatory with stakeholders. For recommendations for future research should be conducted about environmental problems with impact on the health conditions of snakeskin gourami fish farmers, snakeskin gourami fish and the people involved in snakeskin gourami fish farming, including studies on the effectiveness and success of long-term health care models such as health conditions, disease control, injury prevention, and the strong points of communities.

\section{Acknowledgements}

This work was supported by the Thailand Research Fund (TRF) and Huachiew Chalermprakiet University, Thailand.

\section{References}

[1] N Meesil. The Identity of the Pla Salid (Gourami Fish) in the Perspective of those Expert of Samutprakarn Province. Academic conference report in national and international research. In: Proceedings of the $9^{\text {th }}$ Local \& Global Sustainability: Meeting the Challenges \& Sharing the Solution. Suansunandha Rajabhat University, Bangkok, Thailand, 2018, p. 764-73.

[2] Twelfth National Economic and Social Development Plan, Available at: http://www.nesdb.go.th/ ewt_dl_link.php?nid=6422, accessed July 2017.

[3] Department of Fisheries, Ministry of Agriculture and Cooperatives. Gourami fish culture. The Agricultural Co-operative Federation of Thailand, Available at: https://www.fisheries.go.th/itdatabase/dbweb/ebook/pdf, accessed January 2018.

[4] R Thanawat. 2009, Working conditions of labor in the informal economic sector in Thailand. Ph. D. Dissertation. Chulalongkorn University, Bangkok, Thailand.

[5] W Ekburanawat. First Step to Occupational Medicine, Available at: http://www.summacheeva.org/ index_book_54_003_reprint.htm, accessed July 2017.

[6] National Statistical Office, The informal employment survey 2017, Available at: www.m-society. go.th/article_attach/12564/16861.pdf, accessed December 2017.

[7] Public Health. Public Health Statistics A.D. 2015, Available at: http://bps.moph.go.th/new bps/ sites/default/files/health_statistic2558.pdf, accessed December 2017.

[8] K Nuntaboot. The Health Care Community Concept and Design Tools. Aurora Printing, Nontaburi, 2008.

[9] K Khungtumneam. Community health care process: The role of community Nurse. J. Phrapokklao Nurs. College 2016; 27, 140-8.

[10] D Kee and W Karwoswki. An assessment technique for postural loading on the upper body (LUBA): The occupational ergonomics hand book. CRC Press, Boca Raton, 2006, p. 832-9.

[11] Published by the Health and Safety Executive, Assessment of repetitive tasks of the upper limbs (the ART tool), Available at: http://www.hse.gov.uk/pubns/indg438.pdf, accessed August 2017.

[12] R Phalasuek, D Thanomchayathawatch, \& D Songloed. A community participation process in teenage pregnancy prevention. Southern College Netw. J. Nurs. Public Health 2017; 4, $256-67$.

[13] O Kokpol. Intimate Guide Public participation for local administrators. King Prajadhipok's Institute, Nontaburi, 2009.

[14] T Wichianprapha, P Homsin and R Srisuriyawet. Factors affecting health behaviors of health volunteers, Chanthaburi Province. Public Health J. Burapha Univ. 2007; 7, 53-68. 
http://wjst.wu.ac.th

[15] S Sukmark, Y Promsiripaiboon and S Pechmanee. Effects of A competency development program for the village health volunteers responsible for consumer protection in Ban Sadet sub-district, Khiansa district, Suratthani province. Commun. Health Dev. Quart. Khon Kaen Univ. 2015; 4, 1-19.

[16] S Thepphukhieo and S Daenseekaew. Community participation in chemical pesticides prevention for flowers planting and Garland making. J. Nurs. Assoc. Thai. North-Eastern Divis. 2013; 31, 80-9. 